\section{Brain atrophy and alcoholism}

Alcoholism has no satisfactory definition, yet no more useful term is available to describe chronic and deleterious overconsumption. Alcohol is mostly drunk for its pharmacological effects on the nervous system, so not surprisingly the brain is one of the organs that suffers most-along with the liver, which detoxifies the alcohol. The effects on the nervous system include direct intoxication, the consequences of withdrawal after habituation, cerebral vascular events, cerebral trauma related to drunkenness, and the results of secondary nutritional deficiency and of liver disease.

Atrophy of the brain is also difficult to define with precision, but radiological studies have shown a clear reduction in brain volume in many chronic alcoholics. This is at least partially reversible with abstinence. How far these changes may be correlated with defects of cerebral function remains to be established.

Cerebral atrophy may be visualised by air encephalography ${ }^{1}$ and by computed tomography ${ }^{2 \cdot 4}$; both techniques show enlargement of the ventricles and widening of the sulci. These changes slowly resolve with prolonged abstinence. ${ }^{4-6}$ The rate of recovery of the shrinkage of the brain is too gradual for it to be explicable entirely in the terms of a return to normal in its content of water and electrolytes. Other mechanisms that might play a part include the regeneration of glial and neuronal proteins. ${ }^{4}$ Estimations of changes in cerebral water content by magnetic resonance imaging in alcoholics during alcohol withdrawal have yielded conflicting results. Besson and coworkers reported a decreased free water content during intoxication and an increase during withdrawal of alcohol. ${ }^{7}$ Smith and colleagues found the reverse-namely, that the brain became excessively hydrated during alcohol consumption and that abstinence led to its dehydration. $^{8}$

Neuropathological studies in cerebral atrophy have been meagre in the extreme. An attempt to remedy this was recently made by Harper and Kril, who conducted a necropsy study on 26 patients with alcoholism in comparison with 44 controls. ${ }^{9}$ As an index of brain shrinkage they measured the size of the pericerebral space-that part of the intracranial volume not occupied by the brain. This space was found to be greater in the alcoholics, particularly in those with histological evidence of Wernicke's encephalopathy and in those with alcoholic liver disease.

In Wernicke's encephalopathy the lesions have a predominantly periventricular distribution, mainly in the diencephalon and brain stem. These are associated with the classic clinical triad of cognitive dysfunction, ocular abnormalities, and ataxia; associated cerebral atrophy has been reported in a quarter of cases. ${ }^{10}$ Korsakoff's amnestic syndrome, in which the main disturbance is a defect of recent memory, represents a chronic sequel, as probably does alcoholic cerebellar degeneration. Wernicke's encephalopathy is due to thiamine deficiency, but there may also be a hereditary susceptibility related to genetic polymorphism for the transketolase enzyme which requires thiamine as a cofactor. " This potentially treatable complication of alcoholism is often not recognised. Harper found that over four years 51 cases were diagnosed at necropsy in a series reported from Perth, Australia. ${ }^{12}$ Only seven had been recognised during life.

The relation between alcoholic liver disease and brain atrophy is not clearly established. In the necropsy study by Harper and Kril, as already mentioned, the reduction in brain tissue was greater in patients with alcoholic liver disease-and the shrinkage was more severe than in patients with Wernicke's encephalopathy. ${ }^{9}$ In only one instance was there histological evidence of hepatic encephalopathy. Acker and coworkers also reported a positive correlation between ventricular size (assessed by computed tomography) and liver disease identified by biopsy in a group of 41 detoxified chronic alcoholics. ${ }^{13}$ On the other hand, Harper and Kril-in a study so far unpublished-reckoned that thiamine deficiency was the main factor when they made a subjective assessment of cerebral atrophy in 150 chronic alcoholics coming to necropsy. ${ }^{9}$ In that series cerebral atrophy was no greater in those with Wernicke's encephalopathy and alcoholic cirrhosis than in those with Wernicke's encephalopathy alone. It was least in those with cirrhosis alone. Lee and her coworkers studied 37 young alcoholics using computed tomography and liver biopsy specimens and concluded that there was no correlation between atrophy and liver disease. ${ }^{14}$ Nevertheless, four of their seven patients with cirrhosis showed cerebral atrophy.

At present, therefore, and despite evidence from studies in animals, ${ }^{15}$ pathological evidence for direct cerebral damage produced by alcohol remains controversial-apart from the specific lesions of Wernicke's encephalopathy and those related to hepatic encephalopathy. The concept of an "alcoholic dementia"' separate from Korsakoff's syndrome remains unsettled. ${ }^{16}$ Courville believed that alcohol is a frequent cause of diffuse cerebral atrophy, with predominant damage to the frontal lobes, ${ }^{17}$ but others have failed to confirm this. The issue clearly needs detailed quantitative analysis.

The cerebral insults in alcoholics are likely to be multiple. Nutritional deficiencies other than thiamine may also be important. These factors will require much further study to resolve their respective and interacting roles in the production of brain atrophy and dysfunction.

P K ThOMAS

Professor of Neurology,

Royal Free Hospital School of Medicine,

London NW3 2PF

1 Brewer C, Perrett L. Brain damage due to alcohol consumption: an air-encephalographic, psychometric and electro-encephalographic study. $B r \mathcal{F}$ Addict 1971;66:170-82.

2 Wilkinson DA, Carlen PL. Relationship of neuropsychological test performance to brain morphology in amnesic and non-amnesic chronic alcoholics. Acta Psychiatr Scand 1980 286(suppl):89-101.

3 Bergman H, Borg S, Hindmarsh T, Ideström C-M, Mützell S. Computed tomography of the brain and neuropsychological assessment of male alcoholic patients and a random sample from the general male population. Acta Psychiatr Scand 1980;286(suppl):47-56

4 Ron MA, Acker W, Shaw GK, Lishman WA. Computerized tomography of the brain in chronic alcoholism. Brain 1982;105:497-514.

5 Carlen PL, Wortzman G, Holgate RC, Wilkinson DA, Rankin JG. Reversible cerebral atrophy in recently abstinent chronic alcoholics measured by computed tomographic scans. Science 1978;100:1076-8.

6 Artman H, Gall MV, Hacker H, Herrlich J. Reversible enlargement of cerebral spinal fluid spaces in alcoholics. A7NR 1981:2:23-7.

7 Besson JAO, Glen AIM, Foreman EI, et al. Nuclear magnetic resonance observations in alcoholic cerebral disorder and the role of vasopressin. Lancet 1981;ii:923-4.

8 Smith MA, Chick J, Kean DM, et al. Brain water in chronic alcoholic patients measured by magnetic resonance imaging. Lancet $1985 ; \mathrm{i}: 1273-4$.

9 Harper C, Kril J. Brain atrophy in chronic alcoholic patients: a quantitative pathological study. I Neurol Neurosurg Psychiatry 1985;48:211-7.

10 Victor M, Adams RD, Collins GH. The Wernicke-Korsakoff syndrome. A clinical and pathological study of 245 patients, 82 with post-mortem examinations. Oxford: Blackwell, 1971

11 Blass JP, Gibson GE. Abnormality of a thiamine-requiring enzyme in patients with WernickeKorsakoff syndrome. N Engl f Med 1977;297:1367-70.

12 Harper C. Wernicke's encephalopathy: a more common disease than realised. A neuropathological study of 51 cases. I Neurol Neurosurg Psychiatry 1979;42:226-31.

13 Acker W, Aps EJ, Majumdar SK, Shaw GK, Thomson AD. The relationship between brain and liver damage in chronic alcoholic patients. F Neurol Neurosurg Psychiatry 1982;45:984-7.

14 Lee K, Møller L, Hardt F, Haubek A, Jensen E. Alcohol-induced brain and liver damage in young males. Lancet 1979;ii:759-61

15 Riley JN, Walker DW. Morphological alterations in hippocampus after long-term alcoho consumption in mice. Science 1978;201:646-8.

16 Lishman WA. Cerebral disorder in alcoholism. Syndromes of impairment. Brain 1981;104:1-20.

17 Courville CB. The effects of alcohol on the nervous system of man. Los Angeles: San Lucas Press, 1955. 